\title{
Bloodless Outpatient Surgical Treatment of Rectocele and Cystocele under Local Anesthesia
}

\author{
Octacílio Figueirêdo Netto ${ }^{1,2,3,4}$, Priscila Garcia Figueirêdo'1,2,3, Eduardo Garcia Figueirêdo 2,3 , \\ Wildecir Barros ${ }^{4,5}$
}

\author{
${ }^{1}$ Department of Gynecology and Obstetrics, Londrina State University, Londrina, Brazil \\ ${ }^{2}$ Endofemina, Gynecologic Surgery and Laser, Londrina, Brazil \\ ${ }^{3}$ eGyneco.com, Online Vaginal Surgery Course, Londrina, Brazil \\ ${ }^{4}$ Brazilian College of Laser Sculpture, Brasília, Brazil \\ ${ }^{5}$ Bella Forma Laser, Brasília, Brazil \\ Email: octaciliof@uol.com.br
}

How to cite this paper: Netto, O.F., Figueirêdo, P.G., Figueirêdo, E.G. and Barros, W. (2021) Bloodless Outpatient Surgical Treatment of Rectocele and Cystocele under Local Anesthesia. Open Journal of Obstetrics and Gynecology, 11, 569-577. https://doi.org/10.4236/ojog.2021.115053

Received: April 15, 2021

Accepted: May 16, 2021

Published: May 19, 2021

Copyright $\odot 2021$ by author(s) and Scientific Research Publishing Inc. This work is licensed under the Creative Commons Attribution International License (CC BY 4.0).

http://creativecommons.org/licenses/by/4.0/

(c) (i) Open Access

\begin{abstract}
Background: Surgical treatment of rectocele and cystocele is usually performed in a hospital setting under regional (spinal or epidural) or general anesthesia, and patients commonly have to stay in the hospital for at least one or two days. The possibility of performing the surgery under local anesthesia, as an outpatient procedure with minimal bleeding and pain, no surgical assistants, with immediate discharge and, most importantly, without compromising postoperative results, is appealing. To our knowledge, no studies have evaluated whether performing rectocele and/or cystocele rectocele repair under local infiltration anesthesia and without separation of the vaginal mucosa from the underlying fascia achieves these goals. Objective: The aim of this study is to describe a new surgical technique for outpatient treatment of cystocele and rectocele under local anesthesia, and our initial results. Materials and Methods: Forty women underwent outpatient surgical repair of rectocele and/or cystocele between April and September 2020 at the ambulatory procedure room of the authors' clinics. The technique consists of a triangularshaped $\mathrm{CO}_{2}$ laser vaporization or electrocauterization of the posterior and/or anterior vaginal epithelium, followed by plication of the edges of the triangle with 0 polygalactin suture. A perineorrhaphy was always performed concomitantly with rectocele repair, and a transobturator sling was performed in women presenting with concomitant stress urinary incontinence. Postoperative evaluation included POP-Q measurement for each patient six months after the procedure, and resolution of prolapse was considered when anterior and/or posterior vaginal wall presented as stage 0 or 1 . Pre and postoperative POP-Q measurements were analyzed using Wilcoxon signed-rank test. Re-
\end{abstract}


sults: The mean operating time was 21 minutes (range: 14 - 38 minutes). All patients tolerated the procedure well and were discharged immediately afterwards. There were no intraoperative or postoperative complications, and all patients had satisfactory healing of the vaginal mucosa. Bleeding from the rectocele and/or cystocele repair was minimal, and nobody required extraanesthesia or transfer to a hospital surgical theater. At six month follow-up, pre and postoperative POP-Q measurements of points $\mathrm{Ap}, \mathrm{Bp}, \mathrm{Aa}$ and $\mathrm{Ba}$ were all statistically significant (Ap $1.6 \pm 1.2 \times-2.4 \pm 0.9$, Bp $2.6 \pm 1.6 \times-2.7$ \pm 1.4 , Aa $1.4 \pm 1.1 \times-2.3 \pm 0.8$, and $\mathrm{Ba} 2.4 \pm 1.5 \times-2.5 \pm 1.2)$ respectively, revealing satisfactory resolution of both rectocele and cystocele. Conclusion: Our initial results suggest that rectocele and cystocele may be safely and effectively treated under local anesthesia in an outpatient setting using this new technique.

\section{Keywords}

Rectocele, Cystocele, Pelvic Organ Prolapse Repair, Local Anesthesia

\section{Introduction}

Pelvic organ prolapse (POP) is a common condition among women, and the social, psychological and economical cost can be high [1] [2]. Almost 10\% of women will, during their lifetime, need surgery for POP, urinary incontinence, or both. Of these, $30 \%$ will undergo two or more surgical procedures, presenting a challenge to the gynecologic surgeon [3].

Although rectocele and cystocele have traditionally been treated in the operating theatre under regional or general anesthesia, the advantages of local anesthesia are well documented [4]. More specifically, local anesthesia has been shown to have minimal interference with homeostasis, a lower risk of postoperative nausea, and vomiting, cognitive dysfunction, a need for postoperative analgesia, and an earlier fulfillment of discharge criteria. The original publication on the placement of the TVT for stress urinary incontinence emphasized the use of local anesthesia with intravenous sedation [5]. While TVT placement is performed for stress urinary incontinence, patients frequently also present with pelvic relaxation disorders requiring additional repair. While some of these combination surgeries were performed under local anesthesia, most of them required regional or general anesthesia [6] [7].

Bilateral pudendal nerve blocks have been used in elderly patients where general anesthesia was contraindicated [8]. Anterior and posterior colporrhaphies, perineoplasties, enterocele repair, colpocleisis, suburethral slings and vaginal hysterectomies have also been performed under local anesthetic infiltration [9] [10] [11]. However, all of these studies report the use of some form of intravenous or inhalatory sedation, which usually requires the presence of an anesthesiologist.

Although vaginal repair of pelvic organ relaxation using local anesthesia is not 
a new concept, the possibility of performing the surgery with minimal bleeding and postoperative pain, no surgical assistants, with immediate discharge and, most importantly, without compromising results, is appealing. To our knowledge, no studies have evaluated whether performing rectocele and/or cystocele rectocele repair under local infiltration anesthesia without concomitant sedation and without separation of the vaginal mucosa from the underlying fascia achieve these goals.

In this article we describe a new surgical technique for outpatient treatment of rectocele and cystocele under local anesthesia, and our initial results.

\section{Materials and Methods}

Forty women with rectocele and/or cystocele were operated between April and September 2020 at the ambulatory procedure room of the authors' clinics. All signed a written consent form, and their ages ranged from 35 to 69 years, with an average of 49. All had POP symptoms for the last twelve months and stage II-IV cystocele and/or rectocele. The preoperative evaluation consisted of a complete history and pelvic examination, cough stress test and voiding diary. The severity of the prolapse was assessed using the POP Quantification (POP-Q) system adopted by the International Continence Society, which identifies six points in the vagina: points $\mathrm{Aa}$ and $\mathrm{Ba}$ for the anterior wall, $\mathrm{Ap}$ and $\mathrm{Bp}$ for the posterior wall, and $C$ and $D$ for the cervix and vaginal vault [12]. The patient is asked to strain to elicit the POP to its maximum extent, and the lowest extent of any of the six defined points is measured relative to the hymenal ring. If any point reaches close to the hymenal ring, the prolapse is at least stage II and usually symptomatic.

Exclusion criteria were previous vaginal operation for POP or incontinence, pelvic infection, pregnancy, vaginal bleeding of unknown etiology, blood coagulation disorders and pelvic malignancy or previous radiation of the pelvic area. Patients presenting with apical prolapse requiring concomitant suspension, such as uterine procidentia or vaginal vault prolapse were also excluded.

Preoperative and early postoperative evaluation of the patients was conducted and summarized, and data was collected before and at least six months after the operation. Resolution of prolapse was considered when anterior and/or posterior vaginal wall presented as stage 0 or 1 . Pre and postoperative POP-Q measurements were analyzed using Wilcoxon signed-rank test. SPSS 12.0 software (Chicago, IL, USA) was used for data analysis. Differences were considered statistically significant when the $\mathrm{P}$ value was less than 0.05 .

Surgical technique: All surgeries were performed in the office by one of the authors, assisted only by a nurse. Patients were placed in a lithotomy position and the anterior and/or posterior mucosa was infiltrated with with $2 \%$ lidocaine with 1:200.000 epinephrine. The anesthetic was diluted 1/1 with saline and injected with a $30 \mathrm{G}$ needle.

For rectocele repair, an anchoring suture of 0 polygalactin was placed at the 
most cranial portion of the rectocele and pulled upward by the nurse. A Gelpi retractor was placed at the vaginal introitus, thus placing the posterior vaginal wall under tension in a triangular-shaped fashion, with the apex of the triangle at the level of the posterior cul-de-sac and its base located at the vaginal introitus. This triangle posterior vaginal epithelium was then either vaporized using the $\mathrm{CO}_{2}$ laser at 8-12W, UP mode, or cautherized using electrocautery at a low setting (Smartxide ${ }^{2}$, Deka, Florence, Italy) (Figure 1). The edges of the triangle were plicated in a running locked fashion using the anchoring suture, starting at the apex of the triangle and progressing towards its base (Figure 2). In patients

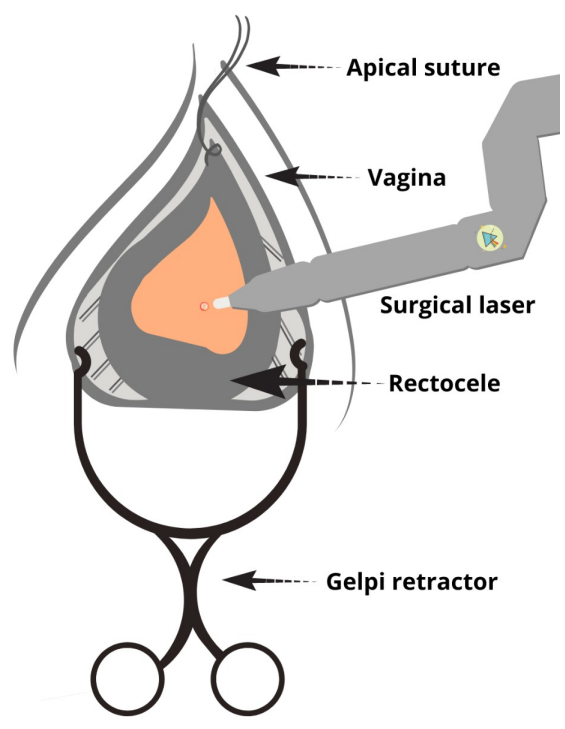

Figure 1. Triangular-shaped $\mathrm{CO}_{2}$ laser vaporization of the posterior vaginal wall.

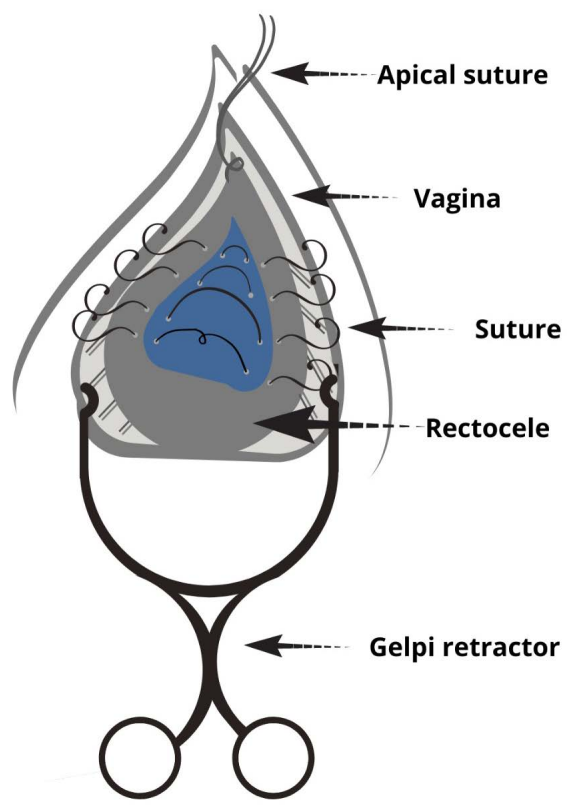

Figure 2. Plication of the edges of the triangle for treatment of rectocele. 
with more severe stage IV rectocele, a second row of plication sutures was performed, invaginating the first row and thus correcting the rectocele. Before ending the plication, the Gelpi retractor was removed and a perineorrhaphy was performed by approximating of the perineal muscles in the midline. For this step of the procedure, additional anesthesia infiltration was performed in a fan-shaped manner at the level of the perineal body. No dissection was performed to separate the posterior vaginal mucosa from the underlying rectovaginal fascia.

The steps for cystocele repair were similar to those for surgical treatment of rectocele repair. A triangular-shaped vaporization or cauterization of the anterior vaginal epithelium was performed using the $\mathrm{CO}_{2}$ laser at 8-12W, UP mode, or the electrocautery at a low setting, respectively. The apex of the triangle extended until $2 \mathrm{~cm}$ from the external urethral meatus, with its base located at the base of the bladder. The edges of the triangle were then plicated with a running-locked suture using 0 polygalactin. This midline plication started at the apex of the triangle and ended at its base, thus reducing the cystocele. In patients with more severe stage IV cystocele, a second row of plication sutures was performed, thus invaginating the first row. Again, no dissection was performed to separate the anterior vaginal mucosa from the underlying pubocervical fascia. In women presenting with concomitant stress urinary incontinence, the bladder was emptied with a metallic canula and a tension-free midurethral transobturator sling was placed after the cystocele was repaired. In these women, the path of the helical needle and site of the skin incision were also infiltrated with the same anesthetic. No vaginal mucosa was excised, and no vaginal pack or indwelling Foley catheter was inserted.

The aim of this study is to present a new surgical technique for outpatient treatment of cystocele and rectocele under local anesthesia, and our initial results.

\section{Results}

The baseline demographic and clinical parameters are shown in Table 1. The

Table 1. Baseline patient characteristics.

\begin{tabular}{cc}
\hline Characteristic & $\mathrm{n}=40$ \\
\hline Age & $49(35-69)$ \\
Parity & $3(0-7)$ \\
Body mass index, $\mathrm{kg} / \mathrm{m}^{2}$ & \\
$<30$ & $25(62.5 \%)$ \\
$30-40$ & $10(25 \%)$ \\
$>40$ & $5(12.5 \%)$ \\
Cystocele & $12(30 \%)$ \\
Rectocele & $17(42.5 \%)$ \\
Cystocele + Rectocele & $11(27.5 \%)$ \\
Concomitant stress urinary incontinence & $11(27.5 \%)$ \\
\hline
\end{tabular}


mean age of the patients was 49 years (range 35 - 69 years), and mean parity was 3 (range $0-7$ ). Fifteen patients $(37.5 \%)$ were considered obese, with a BMI $>30$ $\mathrm{kg} / \mathrm{m}^{2}$. Seventeen patients presented with rectocele stage II - IV, 12 patients with cystocele POP stage II - IV, and 11 patients with rectocele and cystocele stage II IV. Eleven patients underwent concomitant transobturator sling.

The mean operating time was 21 minutes (range: 14 - 38 minutes). All patients tolerated the procedure well and were discharged immediately afterwards. There were no intraoperative or postoperative complications and bleeding was minimal, except for one patient who underwent a concomitant transobturator sling who had moderate bleeding from dissection of the paraurethral tunnels which resolved spontaneouly after the mesh was placed and the anterior vaginal incision closed. All 40 patients had satisfactory healing of the posterior and/or anterior vaginal mucosa, with no instances of suture dehiscence when either the electrocautery or $\mathrm{CO}_{2}$ laser was used. Similarly, all patients were able to void after the procedure, and no urinary retention was observed.

At six month follow-up, pre and postoperative POP-Q measurement of points $\mathrm{Ap}, \mathrm{Bp}, \mathrm{Aa}$ and $\mathrm{Ba}$ were all statistically significant (Ap $1.6 \pm 1.2 \times-2.4 \pm 0.9$, Bp $2.6 \pm 1.6 \times-2.7 \pm 1.4$, Aa $1.4 \pm 1.1 \times-2.3 \pm 0.8$, and $\mathrm{Ba} 2.4 \pm 1.5 \times-2.5 \pm 1.2$ ) respectively, revealing satisfactory resolution of both rectocele and cystocele (Table 2). All patients reported relief of the sensation of vaginal bulge, and were satisfied with the operation.

\section{Discussion}

Since the goal of treating POP is to improve quality of life rather than prolong survival, when choosing a treatment it is important to look for the least invasive method providing the best outcome for the patient, preferably as a single procedure. A conservative approach is a reasonable alternative for mild, asymptomatic cases, but surgical management is usually required for symptomatic grade II - IV vaginal prolapse.

A point that warrants discussion is the need to open the vaginal wall and dissect it from the underlying fascia, followed by midline plication, as has been traditionally done for many decades [13] [14]. The existence of a separate layer of vaginal fascia and the role of this tissue in supporting the urethra and bladder

Table 2. POP-Q measurements.

\begin{tabular}{cccc}
\hline & Before operation & After operation & P value \\
\hline $\mathrm{Ap}(\mathrm{cm})$ & $1.6 \pm 1.2$ & $-2.4 \pm 0.9$ & $<0.001$ \\
$\mathrm{Bp}(\mathrm{cm})$ & $2.6 \pm 1.6$ & $-2.7 \pm 1.4$ & $<0.001$ \\
$\mathrm{Aa}(\mathrm{cm})$ & $1.4 \pm 1.1$ & $-2.3 \pm 0.8$ & $<0.001$ \\
$\mathrm{Ba}(\mathrm{cm})$ & $2.4 \pm 1.5$ & $-2.5 \pm 1.2$ & $<0.001$ \\
$\mathrm{TVL}(\mathrm{cm})$ & $7.76 \pm 0.22$ & $7.98 \pm 0.48$ & 0.44 \\
$\mathrm{C}(\mathrm{cm})$ & $-5.8 \pm 1.4$ & $-6.6 \pm 1.5$ & 0.061 \\
\hline
\end{tabular}


anteriorly and the rectum posteriorly have been an area of controversy for more than a century [15] [16] [17]. The vagina consists of three layers: a mucosal layer consisting of nonkeratinized squamous epithelium overlying a lamina propia; a muscular layer consisting of smooth muscle, collagen, and elastin; and an adventitial layer consisting of collagen and elastin. Histological examination has failed to demonstrate a separate layer of fascia between the vagina and the bladder or rectum, and the tissue labeled as "fascia" may actually be an artifact of surgical dissection represented by portions of the vaginal muscularis. Thus, if one believes this is a reasonable rationale, there is no point in plicating the "fascia" separately from the mucosa.

In 2001, Petros proposed cutting a central "bridge" of tissue in the posterior vaginal wall, followed by destruction of the epithelium with diathermy and full-thickness suture of the lateral flaps in the midline to invaginate the bridge [18]. The purpose was to create a critical structural mass posteriorly so as to prevent rectocele formation. Our technique follows this same principle, except there is no dissection of lateral vaginal flaps or anchoring of tissue, only cauterization or vaporization of the vaginal mucosa, followed by its plication. The choice of using either electrocautery or $\mathrm{CO}_{2}$ laser depended on availability of the equipment at the time of the operation, and the purpose of destroying the vaginal epithelium was to promote adequate healing and avoid the formation of inclusion cysts postoperatively. Both techniques were equally effective in achieving these two goals.

Another topic for consideration is that, because the posterior vaginal mucosa is not opened, our technique does not allow approximation of the levator ani muscles in the midline. Karram and Maher (2013) reviewed the literature concerning the safety and efficacy of surgery for posterior vaginal prolapse, and concluded that midline plication without levatorplasty is the procedure of choice [19]. They also found no evidence to support the use of polypropylene mesh or biological graft in posterior compartment, a fact corroborated by two extensive Cochrane reviews showed that the current evidence does not support the use of any prosthetic material at the time of anterior or posterior vaginal repair, owing to increased morbidity [20] [21]. Thus, if the surgeon has to rely on patient's tissue for long-term results, it makes sense to use as much of it as is available, instead of resecting and discarding redundant vaginal mucosa.

Because this study reports our initial experience with this technique, it has some limitations, namely the small number of patients, short follow-up and absence of a control group were traditional anterior and/or posterior repair was performed in the traditional way, with dissection of vaginal mucosa from the underlying "fascia" under regional or general anesthesia.

On the other hand, in our view the technique presented offers many advantages: minimal bleeding, which also alleviates the need for packing the vagina postoperatively; minimal dissection and tissue manipulation, allowing it to be performed in an outpatient setting, under local anesthesia, quickly and with immediate discharge; and, most importantly, potentially a stronger and more 
durable procedure, since the vaginal tissue containing muscle and collagen is not discarded, but is part of the repair. However, it remains to be seen if these initial results will be confirmed in further trials with larger number of patients and longer follow-up.

\section{Conflicts of Interest}

The authors declare no conflicts of interest regarding the publication of this paper.

\section{References}

[1] Subak, L.L., Waetjen, L.E., van den Eeden, S., Thom, D.H., Vittinghoff, E. and Brown, J.S. (2001) Cost of Pelvic Organ Prolapse Surgery in the United States. $O b$ stetrics \& Gynecology, 98, 646-651. https://doi.org/10.1097/00006250-200110000-00021

[2] Melville, J.L., Fan, M., Rau, H., Nygaard, I.E. and Katon, W.J. (2009) Major Depression and Urinary Incontinence in Women: Temporal Associations in an Epidemiologic Sample. American Journal of Obstetrics and Gynecology, 201, 490-e1. https://doi.org/10.1016/j.ajog.2009.05.047

[3] Olsen, L., Smith, V.J., Bergstrom, J.O., Colling, J.C. and Clark, A.L. (1997) Epidemiology of Surgically Managed Pelvic Organ Prolapse and Urinary Incontinence. $O b$ stetrics \& Gynecology, 89, 501-506. https://doi.org/10.1016/S0029-7844(97)00058-6

[4] Simons, M.P., Aufenacker, T., Bay-Nielsen, M., et al. (2009) European Hernia Society Guidelines on the Treatment of Inguinal Hernia in Adult Patients. Hernia, 13, 343-403. https://doi.org/10.1007/s10029-009-0529-7

[5] Ulmsten, U., Henriksson, L., Johnson, P. and Varhos, G. (1996) An Ambulatory Surgical Procedure under Local Anesthesia for Treatment of Female Urinary Incontinence. International Urogynecology Journal, 7, 81-86.

https://doi.org/10.1007/BF01902378

[6] Jomaa, M. (2000) Combined Tension-Free Vaginal Tape and Prolapse Repair under Local Anaesthesia in Patients with Symptoms of Both Urinary Incontinence and Prolapse. Gynecologic and Obstetric Investigation, 3, 184-186.

https://doi.org/10.1159/000052921

[7] Gordon, D., Gold, R.S., Pauzner, D., Lessing, J.B. and Groutz, A. (2001) Combined Genitourinary Prolapse and Prophylactic Tensionfree Vaginal Tape in Women with Severe Prolapse and Occult Stress Urinary Incontinence: Preliminary Results. Urology, 58, 547-550. https://doi.org/10.1016/S0090-4295(01)01327-9

[8] Miklos, J.R., Sze, E.H.M. and Karram, M.M. (1995) Vaginal Correction of Pelvic Organ Relaxation Using Local Anesthesia. Obstetrics \& Gynecology, 86, 922-924. https://doi.org/10.1016/0029-7844(95)00331-K

[9] Buchsbaum, G.M., Albushies, D.T., Schoenecker, E., Duecy, E.E. and Glantz, J.C. (2006) Local Anesthesia with Sedation for Vaginal Reconstructive Surgery. International Urogynecology Journal, 17, 211-214. https://doi.org/10.1007/s00192-005-1365-7

[10] Kuhn, A., Gelman, W., O’Sullivan, S. and Monga, A. (2006) The Feasibility, Efficacy and Functional Outcome of Local Anaesthetic Repair of Anterior and Posterior Vaginal Wall Prolapse. European Journal of Obstetrics \& Gynecology and Reproductive Biology, 124, 88-92. https://doi.org/10.1016/j.ejogrb.2005.06.009

[11] Athanasiou, S., Zacharakis, D., Grigoriadis, T., Papalios, T., Pitsouni, E., Valsamidis, 
D. and Hadzillia, S. (2020) Vaginal Hysterectomy with Anterior and Posterior Repair for Pelvic Organ Prolapse under Local Anesthesia: Results of a Pilot Study. International Urogynecology Journal, 31, 2109-2116.

https://doi.org/10.1007/s00192-020-04326-0

[12] Bump, R.C., Mattiasson, A., Bo, K., Brubaker, L.P., DeLancey, J.O., Klarskov, P. and Shull, B.L. (1996) The Standardization of Terminology of Female Pelvic Organ Prolapse and Pelvic Floor Dysfunction. American Journal of Obstetrics and Gynecology, 175, 10-17. https://doi.org/10.1016/S0002-9378(96)70243-0

[13] Kelly, H.A. (1914) Urinary Incontinence in Women, Without Manifest Injury to the Bladder. Surgery, Gynecology and Obstetrics, 18, 444.

[14] Weber, M. and Walters, M.D. (1997) Anterior Vaginal Prolapse: Review of Anatomy and Techniques of Surgical Repair. Obstetrics \& Gynecology, 89, 311-318. https://doi.org/10.1016/S0029-7844(96)00322-5

[15] Corton, M. (2009) Anatomy of Pelvic Floor Dysfunction. Obstetrics and Gynecology Clinics of North America, 36, 401-419. https://doi.org/10.1016/j.ogc.2009.09.002

[16] Ricci, J.V. and Thom, C.H. (1954) The Myth of a Surgically Useful Fascia in Vaginal Plastic Reconstructions. Quarterly Review of Surgery, Obstetrics and Gynecology, 2, 253-261.

[17] Uhlenhuth, E. and Nolley, G.W. (1957) Vaginal Fascia, a Myth? Obstetrics \& Gynecology, 10, 349-358.

[18] Papa Petros, P.E. (2001) Vault Prolapse II: Restoration of Dynamic Vaginal Supports by Infracoccygeal Sacropexy, an Axial Day-Case Vaginal Procedure. International Urogynecology Journal, 12, 296-303. https://doi.org/10.1007/PL00004039

[19] Karram, M. and Maher, C. (2013) Surgery for Posterior Vaginal Wall Prolapse. International Urogynecology Journal, 24, 1835-1841.

https://doi.org/10.1007/PL00004039

[20] Maher, C., Feiner, B., Baessler, K., Christmann-Schmid, C., Haya, N. and Brown, J. (2016) Surgery for Women with Anterior Compartment Prolapse. Cochrane Database of Systematic Reviews, No. 11, CD004014. https://doi.org/10.1002/14651858.CD004014.pub6

[21] Mowat, A., Maher, D., Baessler, K., Christmann-Schmid, C., Haya, N. and Maher, C. (2018) Surgery for Women with Posterior Compartment Prolapse. Cochrane Database of Systematic, No. 3, CD012975. https://doi.org/10.1002/14651858.CD012975 